\title{
AOR
}

Selected Papers of \#AolR2021:

The 22nd Annual Conference of the

Association of Internet Researchers

Virtual Event / 13-16 Oct 2021

\section{WHAT IS BEHIND THE (GLASS)DOOR? EXAMINING TOXIC WORKPLACE CULTURES VIA AN EMPLOYMENT REVIEW SITE}

Kelly Bergstrom

York University

\section{Background and Context}

In August 2018, video games news website Kotaku published Cecilia D'Anastasio's (2018) feature-length article relaying the experiences of 28 current and former employees who described working for Riot, the League of Legends developer, as being akin to a fraternity. The article describes a 'bro-culture' where women were overlooked for promotions, but also sexualized by management. Former employees in particular felt frustrated and that they were prevented from speaking freely about their experiences at Riot because of non-disparagement agreements they signed before leaving the company. In the wake of the Kotaku article, Riot created a Diversity and Inclusion Policy and has attempted to make steps towards increasing diversity in their workforce, but 200 Riot employees staged a walkout in protest of the company in May 2019, and then later in the year the company settled a gender discrimination class action lawsuit by agreeing to pay a $\$ 10$ million settlement (Rand, 2019).

Riot Games is just one case in a broader industry that grapples with multiple issues surrounding working conditions. Academic interviews with current, former, and aspirational game workers as well as ethnographic investigations of game development companies are helpful for tracing the contours of an industry that all too often relies on "doing what you love" to excuse not being paid a fair wage, being expected to work in crunch conditions, and/or having to shoulder gender and/or racial stereotypes about who 'should' be working in games (Bulut, 2020; Chee, 2016; Chia, 2019; Whitson, 2019). Indeed, the game industry is an important bellwether for advancements (and setbacks) faced by both tech and cultural workers more broadly conceived.

Narratives of current and former employees are powerful sources of information. For example, in my previous work at AoIR I have examined the wealth of information that can be gleaned from "Why I Quit BuzzFeed" videos posted to YouTube, where former employees frankly discussed the behind the scenes working conditions at BuzzFeed (Bergstrom, 2018). While interviews with current and former workers are important, nondisclosure agreements can make it difficult to locate informants. Those who are willing

Suggested Citation (APA): Bergstrom, K. (2021, October). What Is Behind The (Glass)Door? Examining Toxic Workplace Cultures Via An Employment Review Site. Paper presented at AolR 2021: The 22nd Annual Conference of the Association of Internet Researchers. Virtual Event: AolR. Retrieved from http://spir.aoir.org. 
to speak might only be willing to do so 'off the record' if speaking negatively about their industry will put future job prospects at risk. In an effort to collect data in a way that reduces the risks faced by current employees, game scholars have begun to investigate public texts written for and by game industry professionals. For example, Amanda Cote and Brandon Harris (2020) turned to Game Developer magazine to better understand the habitus of crunch. Suzanne de Castell and Karen Skardzius (2019) sought out incidents of 'public speech' including previously published interviews, corporate employee profiles, and social media posts to examine women's experiences working in the game industry. Taken together, this work demonstrates how public speech can reveal the behind the scenes elements of the games industry that might otherwise be off the record.

\section{Using Glassdoor to peek behind the curtain}

Launched in 2008 as a site to collect the anonymous perspectives of current and former employees as well as their self-reported salaries, Glassdoor has grown to be a top destination for American job seekers wanting to learn more about a company's work environment. Related work in the area has shown that analysis of tech industry-focused materials, such as the textual analysis of job recruitment ads conducted by Brooke Erin Duffy and Becca Schwartz (2018), articulate how the industry has come to expect certain behaviours and attributes of an ideal employee. Sites such as Glassdoor play an important role in hosting discourses that shape the norms and expectations of an industry when it comes to the recruitment ads they host, but Glassdoor specifically offers up a unique perspective in that it allows current and former employees to leave an anonymous review of the company. Employees are asked to evaluate the 'pros' and the 'cons' of a particular company, which can either entice a prospective recruit with details about a particular working environment—or warn them away. While the same sort of caveats surrounding anonymous sources apply here, I argue that Glassdoor provides insights into broad trends and themes that can be further investigated through more traditional qualitative data collection techniques.

I argue that Glassdoor is an easily accessible yet underutilized resource for scholars (both games and culture industries broadly conceived) interested in a peek 'behind the curtain' of industries reliant on non-disclosure and non-disparagement agreements. Here, I report on my ongoing analysis of 740 current and former employee reviews of Riot posted to the website Glassdoor.com between October 2009 and March 2021. Employee review text was captured using the NCapture extension for Nvivo. My preliminary thematic analysis - conducted via Nvivo 11 for windows - found that in the months following D'Anastasio's Kotaku article, employee (former and current) reviews of the company made direct reference about the company's toxic internal culture. In some cases they supported the experiences relayed in D'Anastasio's article, but others refuted it. However, when a more longitudinal approach is taken to analyzing the reviews, evidence of this underlying toxicity actually appears throughout the company's entire history on Glassdoor. For example, an excerpt from the very first employee review posted in 2009 states:

They work a lot of nights and weekends, which is o.k. if your are single. The office humor can be fairly graphic. 
While the reviewer left it vague, fairly graphic humour-when viewed in the context provided by D'Anastasio's interviews with current employees describing toxic masculinity pervading Riot's workplace culture where even men might find themselves having their genitals groped-it becomes much easier to read between the lines. Other themes emerging from the data include extended periods of crunch and how the 'perks' associated with the job (lunches, vacations) are initially appreciated but ultimately not a replacement for a proper work/life balance and appropriate compensation.

Through this thematic analysis of Riot reviews, I argue there is ample evidence to indicate that Glassdoor can be a fruitful venue for media industry scholars interested adding additional sources of data to better understand employee concerns about 'notorious' companies while mitigating potential harm to informants who might otherwise be reluctant to speak 'on the record' about an industry that remains resistant to change.

\section{References}

Bergstrom, K. (2018). What Can "Why I Left Buzzfeed" Vlogs Teach Us About Invisible Labour? AolR Selected Papers of Internet Research. Association of Internet Researchers. https://doi.org/10.5210/spir.v2018i0.10473

Bulut, E. (2020). A precarious game: The illusion of dream jobs in the video game industry. ILR Press, an imprint of Cornell University Press.

Chee, F. M. (2016). A game industry beyond diversity: Systemic barriers to participation in South Korea. In Y. B. Kafai, G. T. Richard, \& B. M. Tynes (Eds.), Diversifying barbie and mortal kombat: Intersectional perspectives and inclusive designs in gaming. ETC Press.

Chia, A. (2019). The Moral Calculus of Vocational Passion in Digital Gaming. Television \& New Media, 20(8), 767-777. https://doi.org/10.1177/1527476419851079

Cote, A. C., \& Harris, B. C. (2020). 'Weekends became something other people did': Understanding and intervening in the habitus of video game crunch. Convergence: The International Journal of Research into New Media Technologies, 135485652091386. https://doi.org/10.1177/1354856520913865

D’Anastasio, C. (2018, August 7). Inside The Culture Of Sexism At Riot Games. Kotaku. https://kotaku.com/inside-the-culture-of-sexism-at-riot-games-1828165483

de Castell, S., \& Skardzius, K. (2019). Speaking in Public: What Women Say about Working in the Video Game Industry. Television \& New Media, 20(8), 836-847. https://doi.org/10.1177/1527476419851078

Duffy, B. E., \& Schwartz, B. (2018). Digital "women's work?": Job recruitment ads and the feminization of social media employment. New Media \& Society, 20(8), 29722989. https://doi.org/10.1177/1461444817738237

Rand, E. (2019, December 2). How we got here: A timeline of the Riot Games cultural controversy. ESPN. https://www.espn.com/esports/story/_id/26686134/how-gothere-line-riot-games-cultural-controversy 
Whitson, J. R. (2019). The New Spirit of Capitalism in the Game Industry. Television \& New Media, 20(8), 789-801. https://doi.org/10.1177/1527476419851086 